Published in final edited form as:

Mol Microbiol. 2003 June ; 48(5): 1377-1387.

\title{
The Cryptococcus neoformans MAP kinase Mpk1 regulates cell integrity in response to antifungal drugs and loss of calcineurin
}

\section{function}

\author{
Peter R. Kraus ${ }^{1}$, Deborah S. Fox ${ }^{1}$, Gary M. Cox ${ }^{1,2}$, and Joseph Heitman ${ }^{1,2,3,4}$ \\ 1 Departments of Molecular Genetics and Microbiology, \\ 2 Medicine, and \\ 3 Pharmacology and Cancer Biology, \\ 4 Howard Hughes Medical Institute, 322 CARL Building, Box 3546, Research Drive, Duke University \\ Medical Center, Durham, NC 27710, USA.
}

\section{Summary}

Cell wall integrity is crucial for fungal growth, development and stress survival. In the model yeast Saccharomyces cerevisiae, the cell integrity Mpk1/Slt2 MAP kinase and calcineurin pathways monitor cell wall integrity and promote cell wall remodelling under stress conditions. We have identified the Cryptococcus neoformans homologue of the $S$. cerevisiae Mpk1/Slt2 MAP kinase and have characterized its role in the maintenance of cell integrity in response to elevated growth temperature and in the presence of cell wall synthesis inhibitors. $C$. neoformans Mpk1 is required for growth at $37^{\circ} \mathrm{C}$ in vitro, and this growth defect is suppressed by osmotic stabilization. $C$. neoformans mutants lacking Mpk1 are attenuated for virulence in the mouse model of cryptococcosis. Phosphorylation of Mpk1 is induced in response to perturbations of cell wall biosynthesis by the antifungal drugs nikkomycin Z (a chitin synthase inhibitor), caspofungin (a $\beta$-1,3-glucan synthase inhibitor), or FK506 (a calcineurin inhibitor), and mutants lacking Mpk1 display enhanced sensitivity to nikkomycin $\mathrm{Z}$ and caspofungin. Lastly, we show that calcineurin and Mpk1 play complementing roles in regulating cell integrity in C. neoformans. Our studies demonstrate that pharmacological inhibition of the cell integrity pathway would enhance the activity of antifungal drugs that target the cell wall.

\section{Introduction}

The fungal cell wall is a dynamic structure that is constantly remodelled during growth, development and during stress (reviewed by Cabib et al., 2001; Klis et al., 2002). A signal transduction pathway that monitors the cell wall and promotes cell wall remodelling has been described in detail in the yeast Saccharomyces cerevisiae (reviewed by Heinisch et al., 1999). The core of the signal transduction pathway responsible for maintaining cell integrity in yeast is a mitogen-activated protein (MAP) kinase cascade. Upstream components of the pathway include membrane sensors that detect stresses to the cell wall (Gray et al., 1997; Verna et al., 1997; Jacoby et al., 1998) and the $\beta$-1,3-glucan synthase subunit Rho1 (Kamada et al., 1996). Rho1 is responsible for activating protein kinase C (PKC), which in turn activates the Mpk1/Slt2 MAP kinase cascade (Torres et al., 1991; Lee et al., 1993). Cell integrity signalling results in the increased expression of numerous genes, many of which encode integral cell wall

*For correspondence at the Department of Molecular Genetics and Microbiology. E-mail heitm001 @ duke.edu; Tel. (+1) 9196842824 ; Fax (+1) 9196845458. 
proteins or enzymes involved in cell wall biosynthesis (Jung and Levin, 1999). An analogous MAP kinase pathway that monitors cell wall integrity and promotes cell wall remodelling under stress conditions has been described in a variety of fungi (Navarro-Garcia et al., 1995; Zaitsevskaya-Carter and Cooper, 1997; Xu et al., 1998; Fox and Smulian, 1999). Importantly, this MAP kinase pathway has been linked to virulence of both plant and animal fungal pathogens, suggesting that cell wall integrity is important for virulence (Diez-Orejas et al., 1997; Xu et al., 1998).

The enzymes that synthesize fungal cell wall components have emerged as attractive targets for the development of new antifungal drugs for two reasons: the cell wall is essential and the enzymes that synthesize cell wall components are not found in human cells. Emphasis on the development of cell wall-directed antifungals has increased on account of the inherent selectivity and fungicidal nature of these compounds (reviewed by Georgopapadakou, 2001). Three classes of cell wall synthesis inhibitors have entered preclinical studies for possible use against systemic fungal infections, and these agents target chitin synthase (nikkomycins), $\beta$-1,3-glucan synthase (echinocandins) and mannoproteins (pradimicins/benanomicins) (Georgopapadakou, 2001). Echinocandins are the only class of cell wall inhibitor still in development, with caspofungin receiving approval for use in treating refractory infections caused by Aspergillus species (reviewed by Hoang, 2001). Echinocandins are not effective against all human pathogenic fungi. For example, caspofungin is relatively ineffective against the important human pathogen Cryptococcus neoformans (Del Poeta et al., 2000).

Cryptococcus neoformans is a human pathogenic fungus that causes life-threatening infections in immunocom-promised hosts, especially patients with AIDS and organ transplant recipients (Casadevall and Perfect, 1998). Virulence factors for C. neoformans include the production of a polysaccharide capsule, melanin synthesis and the ability to grow at $37^{\circ} \mathrm{C}$ (Fromtling et al., 1982; Kwon-Chung et al., 1982; Odom et al., 1997; Waugh et al., 2002). Growth at $37^{\circ} \mathrm{C}$ is a stressful condition that activates the cell integrity MAP kinase pathway in S. cerevisiae (Kamada et al., 1995), suggesting the possibility that a similar cell integrity MAP kinase pathway in C. neoformans could be important for virulence. Furthermore, a cell integrity MAP kinase pathway in $C$. neoformans might be important for responses to antifungal drugs that target the cell wall biosynthetic machinery.

Here, we report the identification and characterization of the $C$. neoformans homologue of the cell integrity MAP kinase Mpk1/Slt2. We determined the role of this MAP kinase, named $\mathrm{Mpk1}$, in growth at elevated temperature, virulence and the response to antifungal drugs. We found that $C$. neoformans $\mathrm{Mpk} 1$ was required for growth at $37^{\circ} \mathrm{C}$ in vitro, and that this growth defect can be suppressed by osmotic stabilization. C. neoformans mutants lacking Mpk1 are attenuated for virulence in the mouse model for cryptococcosis, but are not avirulent. Phosphorylation of Mpk1 is induced in response to perturbations of cell wall biosynthesis by Calcofluor white, nikkomycin $\mathrm{Z}$ and caspofungin. Mpk1 is important for surviving exposure to nikkomycin $\mathrm{Z}$ and caspofungin. Lastly, we have observed a relationship between the calcium/calmodulin-dependent protein phosphatase calcineurin and Mpk1 in regulating cell integrity in C. neoformans. Taken together, our studies highlight the importance of the cell integrity pathway for pathogenesis and as a potential antifungal drug target.

\section{Results}

\section{Identification of the C. neoformans cell integrity MAP kinase homologue Mpk1}

To identify the $C$. neoformans homologue of the cell integrity MAP kinase, BLAST searches of the $C$. neoformans genome database (http://www.tigr.org) were performed using the amino acid sequence of $S$. cerevisiae Slt2/Mpk1 and other MAP kinases. Sequence traces that produced high BLAST scores using Slt2/Mpk1 but not with other $S$. cerevisiae MAP kinase 
sequences were assembled into a $2.6 \mathrm{~kb}$ contig containing the entire $C$. neoformans $M P K 1$ gene. The MPKl open reading frame (ORF) and location of introns was determined by rapid amplification of cDNA ends (RACE), revealing a predicted protein with significant homology to other fungal MAP kinases, including S. cerevisiae Slt2/Mpk1 (60\% identity),

Schizosaccharomyces pombe Spm1 (60\%), Candida albicans Mkc1 (59\%) and Pneumocystis carinii Mkp1 (57\%). These MAP kinases are involved in regulating cell wall integrity in their respective organisms (Martin et al., 1993; Navarro-Garcia et al., 1995; Zaitsevskaya-Carter and Cooper, 1997; Xu et al., 1998; Fox and Smulian, 1999).

\section{MPK1 is required for growth at elevated temperature in C. neoformans}

The function of $M P K 1$ in promoting cell wall integrity at elevated temperature was analysed by gene disruption. An $m p k 1 \triangle:: U R A 5$ DNA construct was used to generate the mutant strain by biolistic transformation and homologous recombination, as described using the serotype $\mathrm{D}$ strain JEC43 as the recipient (Experimental procedures; Davidson et al., 2002). The mutant strain was analysed by Southern blot and polymerase chain reaction (PCR), which showed that the desired double cross-over event occurred at the MPK1 locus without ectopic integrations (Fig. 1A; Davidson et al., 2002). The resulting $m p k l \Delta$ strain exhibited a growth defect at $37^{\circ}$ $\mathrm{C}$ (Fig. 1B and C), which was remediated by providing $1 \mathrm{M}$ sorbitol as an osmotic support (Fig. 1C). Reintroduction of the wild-type $M P K 1$ gene was accomplished by transforming the $m p k 1 \triangle$ mutant (PK1) with a PCR product containing the wild-type MPKl gene (see Experimental procedures) and selecting for gene replacement events on media containing 5fluoroorotic acid (5-FOA). Two transformants were transformed with the URA5 gene to generate uracil prototrophs (PK4 and PK5). Reintroduction of the wild-type MPK1 gene complemented the $m p k l$ mutation and restored the ability to grow at $37^{\circ} \mathrm{C}$ (Fig. 1B). This phenotype is similar to the phenotype of $S$. cerevisiae slt $2 \Delta$ mutants (Fig. 1C; Kamada et al., 1995), suggesting that $C$. neoformans MPKI is important for cell wall integrity at elevated temperature.

\section{The mpk1 $\Delta$ mutant is attenuated for virulence in the mouse model for cryptococcosis}

The ability to grow at elevated temperature is essential for the virulence of $C$. neoformans (Odom et al., 1997; Fox et al., 2001; Waugh et al., 2002). Because the mpkl 1 mutant was unable to grow at $37^{\circ} \mathrm{C}$, we hypothesized that Mpk1 would be required for virulence in the mouse model of cryptococcosis. C5 complement-deficient DBA mice were infected with wildtype and $m p k l \Delta$ strains by lateral tail vein injection and monitored daily for survival. The survival of mice infected with the wild-type strain (JEC21) was significantly reduced compared with mice infected with the $m p k 1 \Delta$ mutant strain $(P<0.001$, Fig. 2A). All 10 mice infected with wild type died by day 100 , whereas all 10 mice infected with the $m p k l \Delta$ mutant survived to day 100 , and six mice were still alive on day 125 . One caveat to this experiment is that molecular events other than the targeted gene disruption can occur during strain construction. To ensure that the mpkl $\Delta$ mutation confers a virulence defect, two strains were isolated in which the $m p k 1$ mutant allele was replaced with the MPKl wild-type gene at its endogenous locus, and uracil prototrophy was restored by ectopic integration of the URA5 gene (see Experimental procedures). Mice were infected with the wild-type strain JEC21, the mpkl $\Delta$ mutant and the two mutant strains reconstituted with the wild-type MPKl gene. This analysis confirmed that the $m p k 1 \Delta$ mutant is attenuated compared with wild type, and introduction of the wild-type $M P K 1$ gene restored virulence in both reconstituted strains $(P<0.001$ for both compared with the mpkl $\Delta$ mutant, Fig. $2 \mathrm{~B}$ ). We note that the relative virulence of the reconstituted strains was greater than that of strain JEC21, which served as a prototrophic wildtype control, and we attribute this to other molecular changes that occurred during either passage of strain JEC 21 or the construction of the reconstituted isolates. In summary, disruption of the MPKl gene attenuates virulence, and this defect is complemented by reintroduction of the wild-type MPK1 gene. 
The $m p k l \Delta$ strain was not avirulent, as has been observed with other $C$. neoformans mutants that are unable to grow at $37^{\circ} \mathrm{C}$ in vitro. After 150 days, the brains of the six surviving mice that received the mpkl $\Delta$ strain were cultured for $C$. neoformans, and four of these mice were culture positive. Three of the four isolated strains were unable to grow at $37^{\circ} \mathrm{C}$ in the absence of osmotic support (Fig. 2C). The fourth strain (BC-4) may have a mutation that suppresses the growth defect at $37^{\circ} \mathrm{C}$ in vitro. $\mathrm{PCR}$ analysis showed that all four strains still contain the $m p k 1 \Delta$ allele (not shown). Consistent with our observations, the cell integrity MAP kinase Mkc1 is important for full virulence of $C$. albicans in the mouse model for candidiasis, but strains lacking $M K C l$ are not avirulent (Diez-Orejas et al., 1997). Taken together, these results suggest that the cell integrity MAP kinase pathway is important for full virulence of $C$.

neoformans, but an intact cell integrity pathway is not an absolute requirement for producing infection.

\section{Perturbation of the cell wall induces Mpk1 phosphorylation}

MAP kinase activation requires dual phosphorylation of conserved threonine and tyrosine residues within the activation loop (reviewed by Cobb and Goldsmith, 1995). To monitor Mpk1 activation, we used a commercially available antiphospho-p44/p42 antibody that can be used to recognize the dually phosphorylated form of Mpk1. Previous studies have established the specificity of this antibody in detecting the dually phosphorylated form of S. cerevisiae Slt2/ Mpk1 (Martin et al., 2000; de Nobel et al., 2000; Harrison et al., 2001). Calcofluor white (CFW) is a fluorescent dye that hinders normal cell wall assembly and has been used to induce activation of the cell wall integrity MAP kinase pathway in $S$. cerevisiae (Pringle et al., 1989; de Nobel et al., 2000). We used CFW to induce activation of $C$. neoformans Mpk1. As shown in Fig. 3A, CFW induces the phosphorylation of Mpk1. The band corresponding to phospho-Mpk1 was absent in $m p k 1 \Delta$ mutant cells. An antibody recognizing the PSTAIRE epitope present in cyclin-dependent kinases served as a loading control.

The echinocandin caspofungin is a specific inhibitor of $\beta$-1,3-glucan synthase, an essential enzyme involved in the synthesis of the fungal cell wall (Douglas et al., 1994; 1997). A single essential gene, FKS1, encodes $\beta$-1,3-glucan synthase in C. neoformans (Thompson et al., 1999). Echinocandins possess in vitro activity against Candida species and other clinically important fungi, but are relatively ineffective against C. neoformans (Del Poeta et al., 1997; 2000; Douglas et al., 1997; Nelson et al., 1997). C. neoformans is sensitive to caspofungin, but only at high concentrations that are not clinically achievable. We detected Mpk1 phosphorylation after treatment with $6 \mu \mathrm{g} \mathrm{ml}^{-1}$ caspofungin for $20 \mathrm{~min}$ (Fig. 3B), indicating that inhibition of $\beta-1,3$-glucan synthase activates the cell integrity MAP kinase pathway in $C$. neoformans. Nikkomycin $\mathrm{Z}$ is a potent inhibitor of chitin synthases, which are also essential for the synthesis of the fungal cell wall (Gaughran et al., 1994; Cabib et al., 2001). Nikkomycin $\mathrm{Z}$ is active against a variety of clinically important fungi in vitro (Hector, 1993; Kim et al., 2002). As shown in Fig. 3B, treatment of $C$. neoformans with $25 \mu \mathrm{g} \mathrm{ml}^{-1}$ nikkomycin $Z$ resulted in the phosphorylation of Mpk1 after $180 \mathrm{~min}$, indicating that the inhibition of chitin synthesis activates the cell integrity MAP kinase pathway.

\section{Enhanced sensitivity of the mpk1 $\Delta$ mutant to nikkomycin $Z$ and caspofungin}

The cell integrity MAP kinase pathway is required for survival during exposure to a variety of agents, including cell wall-degrading enzymes, Calcofluor white, caffeine, vanadate and others (Heinisch et al., 1999; Martin et al., 2000; de Nobel et al., 2000). To test whether $C$. neoformans Mpk1 is required for survival during treatment with caspofungin or nikkomycin $\mathrm{Z}$, we analysed wild-type and mutant cells for growth in the presence of these drugs. Figure 4A shows that the sensitivity to nikkomycin Z is dramatically increased in the absence of Mpk1, which is consistent with our observation that nikkomycin $\mathrm{Z}$ exposure results in the phosphorylation of Mpk1. Cells lacking Mpk1 showed an increase in caspofungin sensitivity 
(Fig. 4B). Caspofungin exhibits synergistic antifungal activity with the calcineurin inhibitor FK506 against $C$. neoformans in vitro (Del Poeta et al., 2000); therefore, we assessed the importance of Mpk1 in the response to caspofungin treatment in the absence of calcineurin function. Figure 4B shows that a cnbl $1 \Delta p k 1 \Delta$ double mutant strain that lacks both the calcineurin B regulatory subunit and the Mpk1 kinase is more sensitive to $4 \mu \mathrm{g} \mathrm{ml}^{-1}$ caspofungin than the $c n b 1 \Delta$ mutant alone, indicating that Mpk1 provides protection against cell wall perturbation in the absence of calcineurin.

\section{Loss of calcineurin function activates FKS1 expression in an Mpk1-dependent manner}

The $F K S 1$ gene encodes a component of the $\beta$-1,3-glucan synthase complex in $C$. neoformans, which is the essential cell wall-synthesizing enzyme targeted by caspofungin (Thompson et al., 1999). In S. cerevisiae, the FKS2 gene, which encodes an alternative subunit of $\beta$-1,3-glucan synthase, is induced when the cell integrity MAP kinase pathway is activated (Jung and Levin, 1999). To test whether the gene encoding $\beta-1,3$-glucan synthase is a target of the cell integrity MAP kinase pathway in $C$. neoformans, expression of $C$. neoformans $F K S 1$ was examined in wild-type, $c n b 1 \Delta, m p k 1 \Delta$ and $c n b 1 \Delta m p k 1 \Delta$ mutant backgrounds by Northern analysis. As shown in Fig. 5, FKS1 expression is markedly induced in the cnb1 $\Delta$ mutant, whereas in the cnbl $\Delta m p k 1 \Delta$ double mutant, there is no such induction. These results implicate the transcriptional regulation of $F K S 1$ as a downstream target of the Mpk1 cell integrity pathway in C. neoformans.

\section{Inhibition of calcineurin by FK506 causes Mpk1 phosphorylation and FKS1 induction}

The role of calcineurin in promoting cell wall integrity at elevated temperature has been established in S. cerevisiae (Zhao et al., 1998). Two results reported here suggest a relationship between calcineurin function and the cell integrity MAP kinase pathway that exists in $C$. neoformans. First, disrupting the cell integrity MAP kinase pathway exacerbates the caspofungin sensitivity of the cnbl $\Delta$ mutant (Fig. 4B). Secondly, loss of calcineurin function results in the induction of the FKS1 gene in an Mpk1-dependent manner (Fig. 5). To test whether loss of calcineurin function results in a change in the phosphorylation state of Mpk1, we analysed protein extracts from a wild-type strain, a cnbl $\Delta$ mutant and a wild-type strain treated with the calcineurin inhibitor FK506 by immunoblot with antiphospho-p44/p42 antibodies. Phosphorylation of Mpk1 increased slightly by $60 \mathrm{~min}$ and was significantly increased at $180 \mathrm{~min}$ after treatment with $5 \mu \mathrm{g} \mathrm{ml}^{-1}$ FK506 (Fig. 6A). A concomitant increase in FKS1 transcription was observed with similar kinetics to the Mpk1 phosphorylation, with a slight increase in transcript levels at $60 \mathrm{~min}$ after FK506 exposure and a greater increase at the 180 minute time point (Fig. 6A). Mpk1 was phosphorylated in the cnbl $1 \Delta$ mutant, which also showed the highest level of FKS1 transcript. The target of FK506 is the immunophilin FKBP12, encoded by the FRR1 gene in C. neoformans (Cruz et al., 1999). FKBP12 and FK506 form a protein-drug complex that inhibits calcineurin (Liu et al., 1991). The C. neoformans frrl-3 allele contains a mutation that alters the hydrophobic drug-binding pocket of FKBP12, and thus abolishes the ability of FKBP12 to inhibit calcineurin in concert with FK506 (Cruz et al., 1999). As shown in Fig. 6B, no induction of phospho-Mpk1 was observed in the frr 1-3 mutant strain, indicating that the effect of FK506 on Mpk1 activation is specific for calcineurin inhibition.

\section{Discussion}

Fungal growth, development and the ability to survive environmental stress are dependent on the integrity of the cell wall. The goal of this study was to determine the role of the MAP kinase Mpk1 in the response to perturbations of cell wall integrity in the pathogenic fungus $C$. neoformans. Here, we report the identification of Mpk1, the C. neoformans homologue of the cell wall integrity MAP kinase. We show that Mpk1 is important for growth at elevated 
temperature and for virulence in the mouse model for cryptococcosis. Furthermore, $C$. neoformans $\mathrm{Mpk} 1$ is activated by phosphorylation in response to treatment with Calcofluor white, the chitin synthase inhibitor nikkomycin $Z$ or the $\beta$-1,3-glucan synthase inhibitor caspofungin. Moreover, Mpk1 provides an additional measure of protection against caspofungin in the absence of calcineurin function. Lastly, we show that inhibition of calcineurin function by FK506 results in the activation of Mpk1 and induction of $F K S 1$, a downstream target of the cell integrity MAP kinase pathway. Taken together, our results show that $C$. neoformans possesses a conserved mechanism for regulating cell integrity in response to perturbations of the cell wall.

The yeast S. cerevisiae is an excellent model system to study the genetic and biochemical mechanisms of MAP kinase pathways (reviewed by Gustin et al., 1998). In recent years, significant progress has been made in the understanding of the MAP kinase pathway involved in the maintenance of cell integrity in S. cerevisiae (Heinisch et al., 1999). A detailed view of the components of this pathway is now available, including the upstream regulatory components, the downstream targets of the pathway and the other cellular processes that are influenced by this pathway (Heinisch et al., 1999). One important aspect of our study was to examine the link between the cell integrity pathway and virulence mechanisms and antifungal drug responses in the human pathogenic fungus $C$. neoformans. In addition to the MAP kinase characterized here, the identification of only one other component of the pathway in $C$. neoformans (Rho1) has been reported (Tanaka et al., 1999; Chang and Penoyer, 2000). The results reported here identify the Mpk1 MAP kinase pathway as an important mechanism for both virulence and the antifungal drug response, and they establish a functional link between the Mpk1 signalling pathway and calcineurin in C. neoformans (Fig. 7). A remarkable aspect of the studies reported here is that the functions of Mpk1 are conserved between $S$. cerevisiae and C. neoformans. This conservation in function is striking given that $S$. cerevisiae is an ascomycete and $C$. neoformans is a basidiomycete, and the two have been diverging over $\approx 500$ million years of evolution. Moreover, in many cases, the physiological functions of highly conserved signalling molecules are quite distinct in these divergent yeasts. For example, the protein phosphatase calcineurin is required for growth at $37^{\circ} \mathrm{C}$, mating and hyphal elongation in C. neoformans, whereas calcineurin is not required for high temperature growth, mating or pseudohyphal filamentous growth in S. cerevisiae (reviewed by Fox and Heitman, 2002). Thus, our finding that the Mpk1 cell wall integrity pathway serves similar roles in these divergent yeasts now allows us to use previous studies in the model budding yeast as a guide to further studies in this fungal pathogen.

The ability to grow at physiological temperatures is a prerequisite for any pathogenic fungus. Mutations in the genes encoding the $C$. neoformans calcineurin catalytic and regulatory subunits result in the inability to grow at physiological temperature, and strains harbouring these mutations are avirulent in the mouse model for cryptococcosis (Odom et al., 1997; Fox et al., 2001). C. neoformans $M P K 1$ is also required for growth at elevated temperature $\left(37^{\circ} \mathrm{C}\right)$, but the ability to grow at this temperature is restored when osmotic support is supplied to the medium. This suggests that the growth defect results from the inability to alter the cell wall in a manner required for growth at $37^{\circ} \mathrm{C}$, as has been shown in S. cerevisiae (Lussier et al., 1997). That the mpkl $\Delta$ mutant is not avirulent suggests that osmotic support sufficient to sustain growth at elevated temperature may be available in vivo (Fig. 2A). All four strains cultured from mouse brains infected with the $m p k 1 \Delta$ mutant still contained the $m p k l \Delta$ allele, and three of these isolates were unable to grow at $37^{\circ} \mathrm{C}$ in the absence of osmotic support in vitro (Fig. 2B), providing additional evidence that the $37^{\circ} \mathrm{C}$ growth defect is partially ameliorated under certain in vivo conditions.

The development of antifungal drugs that target the cell wall has been emphasized in recent years for several reasons, including the fungal-specific nature of their targets 
(Georgopapadakou, 2001). Notably, the $\beta$-1,3-glucan synthase inhibitor caspofungin has recently been approved for use in treating certain fungal infections (Hoang, 2001). Caspofungin is effective against $C$. neoformans only at clinically unachievable concentrations, highlighting the importance of understanding how this pathogenic fungus responds to drugs that target the cell wall synthesis machinery. C. neoformans Mpk1 is activated in response to a variety of perturbations to the cell wall, including Calcofluor white treatment and inhibition of chitin synthesis by nikkomycin Z (Fig. 3A and B). Although caspofungin is relatively ineffective against $C$. neoformans, we show that the activating dual phosphorylation of Mpk1 does occur in the presence of caspofungin. Mpk1 is phosphorylated in response to caspofungin after only 20 min, whereas Mpk1 phosphorylation is not observed after nikkomycin Z treatment until $180 \mathrm{~min}$. This may reflect differences in how the drugs enter the cell or the timing at which the respective enzymes inhibited by these drugs are needed during the cell cycle. Our results are consistent with the observation that $\beta$-1,3-glucan synthesis is inhibited in the presence of caspofungin (Feldmesser et al., 2000). Several explanations have been proposed to explain the ineffectiveness of caspofungin against $C$. neoformans (Thompson et al., 1999; Del Poeta et al., 2000; Feldmesser et al., 2000). $\beta$-1,3-glucan is an essential component of the $C$.

neoformans cell wall, but a reduction in $\beta-1,3$-glucan may be tolerable if other cell wall components are available to compensate for this reduction. In support of this notion, $C$. neoformans strains with no calcineurin function are extremely sensitive to caspofungin (Fig. 4B, Del Poeta et al., 2000).

Calcineurin is a $\mathrm{Ca}^{2+}$ calmodulin-dependent phosphatase that has been implicated in cell wall metabolism in model yeasts (Zhao et al., 1998; Sugiura et al., 2002). Specifically, calcineurin regulates the expression of an alternative $\beta$-1,3-glucan synthase subunit (Fks2) in response to growth at $39^{\circ} \mathrm{C}$ in S. cerevisiae (Zhao et al., 1998). Furthermore, calcineurin is essential in $S$. cerevisiae strains lacking components of the cell integrity pathway (Garrett-Engele et al., 1995). Electron microscopy studies revealed that $C$. neoformans strains lacking calcineurin have an altered cell wall (D. Fox and J. Heitman, unpublished results). The findings reported here support the notion that calcineurin plays an important role in cell wall metabolism in $C$. neoformans. Inhibition of calcineurin by FK506 results in activation of Mpk1 and the induction of a downstream component of the cell integrity pathway, FKS1. A mutant with an altered FKBP12 that cannot bind FK506 to inhibit calcineurin does not accumulate activated Mpk1 in the presence of FK506, indicating that the effect of FK506 on the phosphorylation state of Mpk1 is specific for calcineurin inhibition by the FKBP12-FK506 complex.

Although the function of Mpk1 in promoting growth at $37^{\circ} \mathrm{C}$ in S. cerevisiae and C. neoformans is conserved, several important differences exist with respect to the relationship between calcineurin and the Mpk1-mediated cell integrity pathway. First, although both fungi possess an Mpk1-dependent component in the regulation of $\beta$-1,3-glucan synthase genes, loss of calcineurin function results in the induction of $F K S 1$ expression in C. neoformans, whereas full FKS2 induction in S. cerevisiae requires calcineurin function (Zhao et al., 1998). Secondly, calcineurin is essential in $S$. cerevisiae strains lacking a functional cell integrity pathway

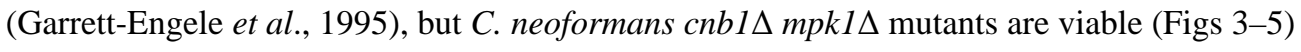
and $m p k l \Delta$ mutants are not hypersensitive to calcineurin inhibitors (data not shown). These differences may reflect differences in the requirements for regulating cell wall integrity in pathogenic fungi compared with a non-pathogenic model yeast. The specific nature of the cell wall defect in the absence of calcineurin in C. neoformans remains to be determined. Systematic identification of protein complexes in $S$. cerevisiae showed that the calcineurin regulatory subunit interacts with Kre6, which is a component of $\beta-1,6$-glucan synthase (Roemer et al., 1993; Ho et al., 2002). If such an interaction exists in C. neoformans, disrupting this interaction may account for the cell wall defects leading to activation of Mpk1 and the altered response to caspofungin in the absence of calcineurin function. 


\section{Experimental procedures}

\section{Strains and growth media}

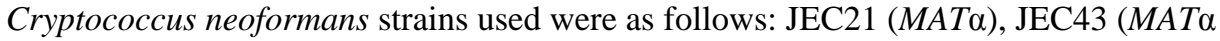

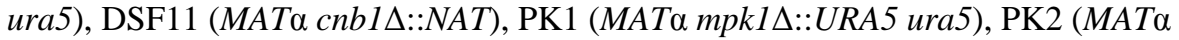

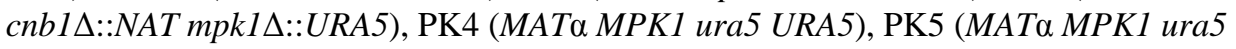

URA5) and C21F3 (MATa frr1-3). S. cerevisiae strains used were W303 (trp1-1 leu2-3112 ura3-1 ade2-1 his3-11 can 1-100) and DLY4914 (W303 mpk1 $\Delta:: H I S 3$ ). All strains were grown in YPD (1\% yeast extract, $2 \%$ peptone, $2 \%$ dextrose) or SD media lacking uracil (Sherman, 1991). Where indicated, sorbitol was added to media at a concentration of $1 \mathrm{M}$. Caspofungin (MK-0991) was generously provided by Merck and Co., nikkomycin Z and Calcofluor white were obtained from Sigma, and FK506 was generously provided by Fujisawa.

\section{Identification, disruption and reconstitution of MPK1}

The $M P K 1$ gene was identified as a sequence trace from the $C$. neoformans genome project, The Institute for Genomic Research (http://www.tigr.org), funded by the NIAID/NIH under grant number AI48594-01. PCR primers JOHE7288 (5'-

ACTAGGCGTGCCATTGTTTAC-3') and JOHE7289 (5'-

GCGGACTGGGCAGGAGAAGC- $3^{\prime}$ ) were used to amplify a $2.4 \mathrm{~kb}$ product containing the entire MPK1 gene. The MPK1 ORF and the location of introns were confirmed by rapid amplification of cDNA ends (RACE) using the SMART ${ }^{\mathrm{TM}}$ RACE cDNA amplification kit (Clontech). The MPK1 cDNA sequence was deposited in GenBank under accession number AY212947. The MPK1 gene from strain JEC43 was disrupted with the URA5 cassette using a modified PCR overlap procedure described by Davidson et al. (2002). Transformations were performed as described previously (Toffaletti and Perfect, 1994) using a Bio-Rad model PDS-1000/He biolistic particle delivery system. Transformants were selected on defined media lacking uracil (Sherman, 1991) with $1 \mathrm{M}$ sorbitol for osmotic support, and the presence of the disruption allele was confirmed by Southern analysis of genomic DNA (Davidson et al., 2002) and by PCR (see below). Strains PK4 and PK5 were constructed by transforming the $m p k 1 \triangle$ mutant (PK1) with a PCR product containing the wild-type $M P K 1$ gene. Transformants were grown on media containing $1 \mu \mathrm{g} \mathrm{ml}^{-1} 5$-fluoroorotic acid (5-FOA) to select for a gene replacement event. Two 5-FOA-resistant isolates were then transformed with a plasmid containing the URA5 gene to generate uracil prototrophs (PK4 and PK5).

\section{Virulence assay}

In vivo testing of $C$. neoformans strains was performed in 4-to 6-week-old female C5 complement-deficient DBA mice (NCI/Charles River Laboratories) using lateral tail vein injections. Strains to be analysed were precultured in YPD at $25^{\circ} \mathrm{C}$ for $24 \mathrm{~h}$, washed with phosphate-buffered saline (PBS) and resuspended in PBS at a concentration of $10^{7}$ cells $\mathrm{ml}^{-1}$. Ten mice were infected with $10^{6}$ cells of each strain in a volume of $100 \mu \mathrm{l}$ via lateral tail vein injection as described previously (Cruz et al., 2000; Fox et al., 2001).

\section{Growth assay}

The sensitivity of $C$. neoformans strains to caspofungin and nikkomycin $\mathrm{Z}$ was assayed by growth inhibition as described previously (de Nobel et al., 2000). Cells were precultured in YPD at $25^{\circ} \mathrm{C}$ for $16-20 \mathrm{~h}$ before dilution to an $\mathrm{OD}_{600}$ of 0.025 . Growth was continued in the presence of caspofungin or nikkomycin $\mathrm{Z}$ in flat-bottomed 96 -well microtitre plates at $25^{\circ} \mathrm{C}$ without shaking. Growth was determined after $48 \mathrm{~h}$ as the $\mathrm{OD}_{600}$ of each culture after resuspension. 


\section{Northern analysis}

Strains for Northern analysis were precultured at $25^{\circ} \mathrm{C}$ for $16-20 \mathrm{~h}$, diluted to an $\mathrm{OD}_{600}$ of 0.2 and incubated for $2-4 \mathrm{~h}$ before drug addition. Total RNA was prepared using acid phenol as described previously (Ausubel et al., 1992). Total RNA (20 $\mu \mathrm{g})$ was separated by electrophoresis in $1.2 \%$ formaldehyde agarose gels and transferred to Nytran SuPerCharge nylon membranes (Schleicher and Schuell). Fragments of the FKS1, GPD1 and ACT1 genes were amplified by PCR, labelled with $\left[\alpha_{-}{ }^{32} \mathrm{P}\right]-\mathrm{dCTP}$ using the Rediprime ${ }^{\mathrm{TM}}$ random prime labelling system (Amersham Pharmacia Biotech) and used as probes for Northern hybridization.

\section{Protein extraction and Western blots}

All strains for protein extraction were precultured at $25^{\circ} \mathrm{C}$ for $16-20 \mathrm{~h}$, diluted to an $\mathrm{OD}_{600}$ of 0.2 and incubated for $2-4 \mathrm{~h}$ before drug addition. Cells were centrifuged and frozen in dry ice before protein extraction. Protein extracts were prepared from cell pellets by glass bead homogenization in $0.5 \mathrm{ml}$ of lysis buffer [50 mM Tris, $\mathrm{pH} 7.5,2 \mathrm{mM} \mathrm{MgCl}_{2}, 1 \times$ protease inhibitor cocktail set IV (Calbiochem), 1× phosphatase inhibitor sets I and II (Calbiochem), and $10 \%$ glycerol] with five 1 min bursts with cooling on ice. Extracts were centrifuged at 14 $000 \mathrm{~g}$ for $10 \mathrm{~min}$ at $4^{\circ} \mathrm{C}$ and the supernatants were collected. Protein concentrations were determined with the Bio-Rad protein assay.

For Western blots, $50 \mu \mathrm{g}$ of total extract was separated by $12 \%$ SDS-PAGE gels and transferred to polyvinylidene difluoride (PVDF) membranes (Bio-Rad). Membranes were probed with antiphospho-p44/42 MAP kinase (Thr-202/Tyr-204) antibody (New England Biolabs) at a 1:4000 dilution to detect active Mpk1. As a control for loading, anti-PSTAIRE antibody (Santa Cruz Biotechnology) was used at a 1:2000 dilution. Primary antibodies were detected using a horseradish peroxidase (HRP)-conjugated anti-rabbit IgG and ECL detection reagents (Amersham Pharmacia Biotech).

\section{Acknowledgements}

We thank Danny Lew for providing yeast strains, Alexander Idnurm for critical reading of the manuscript, and Rebecca Casey for assistance with manuscript preparation. These studies were supported in part by R01 grants AI39115, AI42159, and AI50438 from NIAID to J.H., and program project grant P01-AI44975 from NIAID to the Duke University Mycology Research Unit. Gary Cox is a Burroughs Wellcome New Investigator in Molecular Pathogenic Mycology. Joseph Heitman is a Burroughs Wellcome Scholar in Molecular Pathogenic Mycology and an Associate Investigator of the Howard Hughes Medical Institute.

\section{References}

Ausubel, FM.; Brent, R.; Kingston, RE.; Moore, DD.; Seidman, JG.; Smith, JA.; Struhl, K. Current Protocols in Molecular Biology. New York: Greene Publishing Associates and Wiley-Interscience; 1992.

Cabib E, Roh DH, Schmidt M, Crotti LB, Varma A. The yeast cell wall and septum as paradigms of cell growth and morphogenesis. J Biol Chem 2001;276:19679-19682. [PubMed: 11309404]

Casadevall, A.; Perfect, JR. Cryptococcus neoformans. Washington, DC: American Society for Microbiology Press; 1998.

Chang YC, Penoyer LA. Properties of various Rhol mutant alleles of Cryptococcus neoformans. J Bacteriol 2000;182:4987-4991. [PubMed: 10940044]

Cobb MH, Goldsmith EJ. How MAP kinases are regulated. J Biol Chem 1995;270:14843-14846. [PubMed: 7797459]

Cruz MC, Cavallo LM, Görlach JM, Cox G, Perfect JR, Cardenas ME, Heitman J. Rapamycin antifungal action is mediated via conserved complexes with FKBP12 and TOR kinase homologs in Cryptococcus neoformans. Mol Cell Biol 1999;19:4101-4112. [PubMed: 10330150] 
Cruz MC, Sia RAL, Olson M, Cox GM, Heitman J. Comparison of the roles of calcineurin in physiology and virulence in serotype D and serotype A strains of Cryptococcus neoformans. Infect Immun 2000;68:982-985. [PubMed: 10639477]

Davidson RC, Blankenship JR, Kraus PR, de Jesus-Berrios M, Hull CM, D’Souza C, et al. A PCR-based strategy to generate integrative targeting alleles with large regions of homology. Microbiology 2002;148:2607-2615. [PubMed: 12177355]

Del Poeta M, Schell WA, Perfect JR. In vitro antifungal activity of pneumocandin L-743,872 against a variety of clinically important molds. Antimicrob Agents Chemother 1997;41:1835-1836. [PubMed: 9257774]

Del Poeta M, Cruz MC, Cardenas ME, Perfect JR, Heitman J. Synergistic antifungal activities of bafilomycin A(1), fluconazole, and the pneumocandin MK-0991/caspofungin acetate (L-743,873) with calcineurin inhibitors FK506 and L-685,818 against Cryptococcus neoformans. Antimicrob Agents Chemother 2000;44:739-746. [PubMed: 10681348]

Diez-Orejas R, Molero G, Navarro-Garcia F, Pla J, Nombela C, Sanchez-Perez M. Reduced virulence of Candida albicans $M K C 1$ mutants: a role for mitogen-activated protein kinase in pathogenesis. Infect Immun 1997;65:833-837. [PubMed: 9009353]

Douglas CM, Foor F, Marrinan JA, Morin N, Nielsen JB, Dahl AM, et al. The Saccharomyces cerevisiae FKS1 (ETG1) gene encodes an integral membrane protein which is a subunit of 1,3- $\beta$-D-glucan synthase. Proc Natl Acad Sci USA 1994;91:12907-12911. [PubMed: 7528927]

Douglas CM, D’Ippolito JA, Shei GJ, Meinz M, Onishi J, Marrinan JA, et al. Identification of the FKS1 gene of Candida albicans as the essential target of 1,3- $\beta$-D-glucan synthase inhibitors. Antimicrob Agents Chemother 1997;41:2471-2479. [PubMed: 9371352]

Feldmesser M, Kress Y, Mednick A, Casadevall A. The effect of the echinocandin analogue caspofungin on cell wall glucan synthesis by Cryptococcus neoformans. J Infect Dis 2000;182:1791-1795. [PubMed: 11069257]

Fox DS, Heitman J. Good fungi gone bad: the corruption of calcineurin. Bioessays 2002;24:894-903. [PubMed: 12325122]

Fox D, Smulian AG. Mitogen-activated protein kinase Mkp1 of Pneumocystis carinii complements the slt2 $\Delta$ defect in the cell integrity pathway of Saccharomyces cerevisiae. Mol Microbiol 1999;34:451462. [PubMed: 10564487]

Fox DS, Cruz MC, Sia RA, Ke H, Cox GM, Cardenas ME, Heitman J. Calcineurin regulatory subunit is essential for virulence and mediates interactions with FKBP12-FK506 in Cryptococcus neoformans. Mol Microbiol 2001;39:835-849. [PubMed: 11251806]

Fromtling RA, Shadomy HK, Jacobson ES. Decreased virulence in stable acapsular mutants of Cryptococcus neoformans. Mycopathologia 1982;79:23-29. [PubMed: 6750405]

Garrett-Engele P, Moilanen B, Cyert MS. Calcineurin, the $\mathrm{Ca}^{2+} /$ calmodulin dependent protein phosphatase, is essential in yeast mutants with cell integrity defects and in mutants that lack a functional vacuolar $\mathrm{H}^{+}$-ATPase. Mol Cell Biol 1995;15:4103-4114. [PubMed: 7542741]

Gaughran JP, Lai MH, Kirsch DR, Silverman SJ. Nikkomycin Z is a specific inhibitor of Saccharomyces cerevisiae chitin synthase isozyme Chs3 in vitro and in vivo. J Bacteriol 1994;176:5857-5860. [PubMed: 8083179]

Georgopapadakou NH. Update on antifungals targeted to the cell wall: focus on beta-1,3-glucan synthase inhibitors. Expert Opin Invest Drugs 2001;10:269-280.

Gray JV, Ogas JP, Kamada Y, Stone M, Levin DE, Herskowitz I. A role for the Pkc1 MAP kinase pathway of Saccharomyces cerevisiae in bud emergence and identification of a putative upstream regulator. EMBO J 1997;16:4924-4937. [PubMed: 9305635]

Gustin MC, Albertyn J, Alexander M, Davenport K. MAP kinase pathways in the yeast Saccharomyces cerevisiae. Microbiol Mol Biol Rev 1998;62:1264-1300. [PubMed: 9841672]

Harrison JC, Bardes ES, Ohya Y, Lew DJ. A role for the Pkc1p/Mpk1p kinase cascade in the morphogenesis checkpoint. Nature Cell Biol 2001;3:417-420. [PubMed: 11283616]

Hector RF. Compounds active against cell walls of medically important fungi. Clin Microbiol Rev 1993;6:1-21. [PubMed: 8457977] 
Heinisch JJ, Lorberg A, Schmitz HP, Jacoby JJ. The protein kinase C-mediated MAP kinase pathway involved in the maintenance of cellular integrity in Saccharomyces cerevisiae. Mol Microbiol 1999;32:671-680. [PubMed: 10361272]

Ho Y, Gruhler A, Heilbut A, Bader GD, Moore L, Adams SL, et al. Systematic identification of protein complexes in Saccharomyces cerevisiae by mass spectrometry. Nature 2002;415:180-183. [PubMed: 11805837]

Hoang A. Caspofungin acetate: an antifungal agent. Am J Health Syst Pharm 2001;58:1206-1214. [PubMed: 11449878]

Jacoby JJ, Nilius SM, Heinisch JJ. A screen for upstream components of the yeast protein kinase C signal transduction pathway identifies the product of the $S L G 1$ gene. Mol Gen Genet 1998;258:148-155. [PubMed: 9613583]

Jung US, Levin DE. Genome-wide analysis of gene expression regulated by the yeast cell wall integrity signalling pathway. Mol Microbiol 1999;34:1049-1057. [PubMed: 10594829]

Kamada Y, Jung US, Piotrowski J, Levin DE. The protein kinase C-activated MAP kinase pathway of Saccharomyces cerevisiae mediates a novel aspect of the heat shock response. Genes Dev 1995;9:1559-1571. [PubMed: 7628692]

Kamada Y, Qadota H, Python CP, Anraku Y, Ohya Y, Levin DE. Activation of yeast protein kinase C by Rho1 GTPase. J Biol Chem 1996;271:9193-9196. [PubMed: 8621575]

Kim MK, Park HS, Kim CH, Park HM, Choi W. Inhibitory effect of nikkomycin Z on chitin synthases in Candida albicans. Yeast 2002;19:341-349. [PubMed: 11870857]

Klis FM, Mol P, Hellingwerf K, Brul S. Dynamics of cell wall structure in Saccharomyces cerevisiae. FEMS Microbiol Rev 2002;26:239-256. [PubMed: 12165426]

Kwon-Chung KJ, Polacheck I, Popkin TJ. Melanin-lacking mutants of Cryptococcus neoformans and their virulence for mice. J Bacteriol 1982;150:1414-1421. [PubMed: 6804444]

Lee KS, Irie K, Gotoh Y, Watanabe Y, Araki H, Nishida E, et al. A yeast mitogen-activated protein kinase homolog (Mpk1p) mediates signalling by protein kinase C. Mol Cell Biol 1993;13:3067-3075. [PubMed: 8386319]

Liu J, Farmer JD Jr, Lane WS, Friedman J, Weissman I, Schreiber SL. Calcineurin is a common target of cyclophilin-cyclosporin A and FKBP-FK506 complexes. Cell 1991;66:807-815. [PubMed: 1715244]

Lussier M, White AM, Sheraton J, di Paolo T, Treadwell J, Southard SB, et al. Large scale identification of genes involved in cell surface biosynthesis and architecture in Saccharomyces cerevisiae. Genetics 1997;147:435-450. [PubMed: 9335584]

Martin H, Arroyo J, Sanchez M, Molina M, Nombela C. Activity of the yeast MAP kinase homologue Slt2 is critically required for cell integrity at $37^{\circ} \mathrm{C}$. Mol Gen Genet 1993;241:177-184. [PubMed: 8232202]

Martin H, Rodriguez-Pachon JM, Ruiz C, Nombela C, Molina M. Regulatory mechanisms for modulation of signaling through the cell integrity Slt2-mediated pathway in Saccharomyces cerevisiae. J Biol Chem 2000;275:1511-1519. [PubMed: 10625705]

Navarro-Garcia F, Sanchez M, Pla J, Nombela C. Functional characterization of the MKC1 gene of Candida albicans, which encodes a mitogen-activated protein kinase homolog related to cell integrity. Mol Cell Biol 1995;15:2197-2206. [PubMed: 7891715]

Nelson PW, Lozano-Chiu M, Rex JH. In vitro growth-inhibitory activity of pneumocandins L-733,560 and L-743,872 against putatively amphotericin B- and fluconazole-resistant Candida isolates: influence of assay conditions. J Med Vet Mycol 1997;35:285-287. [PubMed: 9292427]

de Nobel H, Ruiz C, Martin H, Morris W, Brul S, Molina M, Klis FM. Cell wall perturbation in yeast results in dual phosphorylation of the Slt2/Mpk1 MAP kinase and in an Slt2-mediated increase in FKS2-lacZ expression, glucanase resistance and thermotolerance. Microbiology 2000;146:21212132. [PubMed: 10974100]

Odom A, Muir S, Lim E, Toffaletti DL, Perfect J, Heitman J. Calcineurin is required for virulence of Cryptococcus neoformans. EMBO J 1997;16:2576-2589. [PubMed: 9184205]

Pringle JR, Preston RA, Adams AEM, Stearns T, Drubin DG, Haarer BK, Jones EW. Fluorescence microscopy methods for yeast. Methods Cell Biol 1989;31:357-435. [PubMed: 2476649] 
Roemer T, Delaney S, Bussey H. SKN1 and KRE6 define a pair of functional homologs encoding putative membrane proteins involved in beta-glucan synthesis. Mol Cell Biol 1993;13:4039-4048. [PubMed: 8321211]

Sherman, F. Getting started with yeast. In: Guthrie, C.; Fink, GR., editors. Methods in Enzymology. 194. San Diego, CA: Academic Press; 1991. p. 3-21.

Sugiura R, Sio SO, Shuntoh H, Kuno T. Calcineurin phosphatase in signal transduction: lessons from fission yeast. Genes Cells 2002;7:619-627. [PubMed: 12081640]

Tanaka K, Nambu H, Kai M, Hidaka Y. Molecular cloning of homologs of RAS and RHO1 genes from Cryptococcus neoformans. Yeast 1999;15:1133-1139. [PubMed: 10455236]

Thompson JR, Douglas CM, Li W, Jue CK, Pramanik B, Yuan X, et al. A glucan synthase FKS1 homolog in Cryptococcus neoformans is single copy and encodes an essential function. J Bacteriol 1999;181:444-453. [PubMed: 9882657]

Toffaletti, DL.; Perfect, JR. Biolistic DNA delivery for Cryptococcus neoformans transformation. In: Maresca, B.; Kobayashi, GS., editors. Molecular Biology of Pathogenic Fungal: a Laboratory Manual. New York: Telos Press; 1994. p. 303-308.

Torres L, Martin H, Garcia-Saez MI, Arroyo J, Molina M, Sanchez M, Nombela C. A protein kinase gene complements the lytic phenotype of Saccharomyces cerevisiae lyt 2 mutants. Mol Microbiol 1991;5:2845-2854. [PubMed: 1779770]

Verna J, Lodder A, Lee K, Vagts A, Ballester R. A family of genes required for maintenance of cell wall integrity and for the stress response in Saccharomyces cerevisiae. Proc Natl Acad Sci USA 1997;94:13804-13809. [PubMed: 9391108]

Waugh MS, Nichols CB, DeCesare CM, Cox GM, Heitman J, Alspaugh JA. Ras1 and Ras2 contribute shared and unique roles in physiology and virulence of Cryptococcus neoformans. Microbiology 2002;148:191-201. [PubMed: 11782511]

$\mathrm{Xu}$ JR, Staiger CJ, Hamer JE. Inactivation of the mitogen-activated protein kinase Mps1 from the rice blast fungus prevents penetration of host cells but allows activation of plant defense responses. Proc Natl Acad Sci USA 1998;95:12713-12718. [PubMed: 9770551]

Zaitsevskaya-Carter T, Cooper JA. Spm1, a stress-activated MAP kinase that regulates morphogenesis in S. pombe. EMBO J 1997;16:1318-1331. [PubMed: 9135147]

Zhao C, Jung US, Garrett-Engele P, Roe T, Cyert MS, Levin DE. Temperature-induced expression of yeast FKS2 is under the dual control of protein kinase C and calcineurin. Mol Cell Biol 1998;18:10131022. [PubMed: 9447998] 

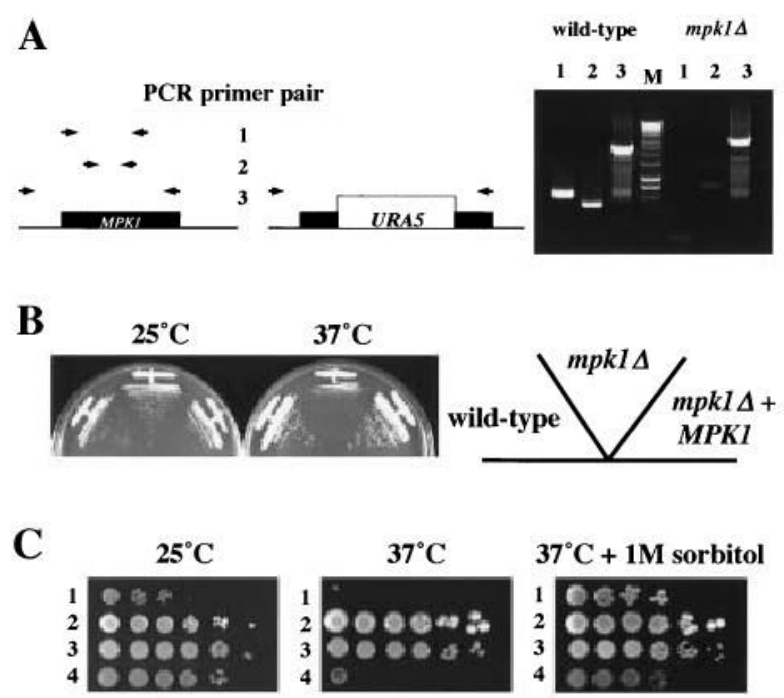

1. S. cerevisiae mpk1 $\Delta$

2. S. cerevisiae wild-type

3. C. neoformans wild-type

4. C. neoformans mpkl $\Delta$

Fig. 1. The mpk1 $\Delta$ mutant displays an osmotically remediable growth defect at $37^{\circ} \mathrm{C}$

A. Confirmation of $m p k l \Delta$ gene disruption by PCR. Genomic DNA was isolated from wildtype and mpkl $\Delta$ strains and used as a template for PCR using primer sets 1, 2 and 3. Primer sets 1 and 2 anneal to sequences deleted in the $m p k 1 \Delta$ allele. M, marker.

B. The $m p k 1 \Delta$ mutant displays a growth defect at $37^{\circ} \mathrm{C}$. Strains were inoculated on YPD media and incubated for $48 \mathrm{~h}$ at the indicated temperatures. Strains used were wild type (JEC21), the $m p k 1 \Delta$ mutant (PK1) and an mpk $1 \Delta$ mutant reconstituted with the wild-type $M P K 1$ gene (PK4). C. The temperature-sensitive growth defects of the $C$. neoformans mpkl $\Delta$ mutant and the $S$. cerevisiae slt $2 \Delta$ mutant are osmotically remediable. Fivefold serial dilutions of cell suspensions of the $S$. cerevisiae slt2 $\Delta$ mutant (DLY4914, row 1), S. cerevisiae wild type (W303, row 2), C. neoformans wild type (JEC21, row 3) and the C. neoformans mpk1 $\Delta$ mutant (PK1, row 4) were inoculated on YPD or YPD $+1 \mathrm{M}$ sorbitol and incubated at the indicated temperatures for $48 \mathrm{~h}$. 


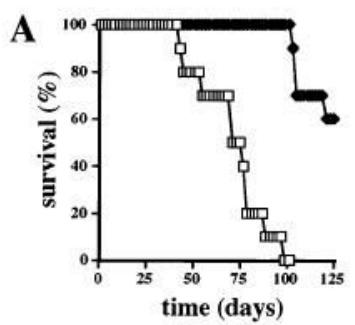

C

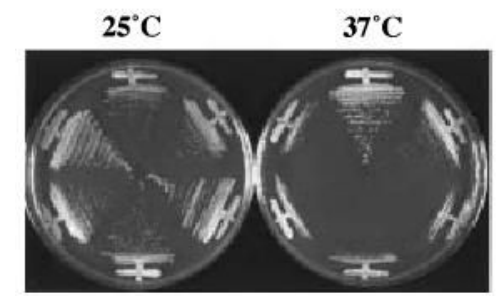

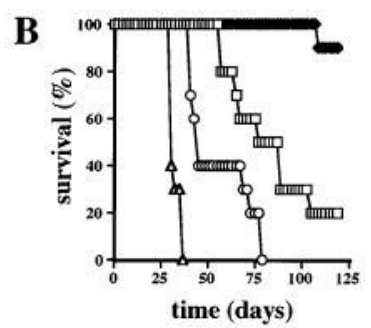

time (days)

Fig. 2. mpk1 $\Delta$ mutants are attenuated for virulence in the mouse model of cryptococcosis A. C5 complement-deficient DBA mice (10 each) were injected via the lateral tail vein with $10^{6}$ cells of a wild-type strain (JEC21, open squares) and the mpkl $\Delta$ mutant (PK1, closed diamonds). Mice were monitored daily for survival over a period of 125 days.

B. C5 complement-deficient DBA mice (10 each) were injected via the lateral tail vein with $10^{6}$ cells of wild-type strain JEC21 (open squares), two $m p k 1 \Delta$ mutant strains reconstituted with the wild-type $M P K 1$ gene (PK4, open triangles; and PK5, open circles) and the mpkl $\Delta$ mutant (PK1, closed diamonds). Mice were monitored daily over a period of 120 days. C. $m p k 1 \Delta$ mutant strains cultured from infected animals still display the in vitro growth defect at $37^{\circ} \mathrm{C}$. C. neoformans was cultured from the brains of four out of the six mice that survived to 150 days after receiving injections of $m p k 1 \Delta$ cells in (A). The strains recovered from these four mice (BC1-4) were inoculated on YPD with wild-type (JEC21) and $m p k 1 \Delta$ mutant (PK1) cells and incubated at the indicated temperature for $48 \mathrm{~h}$. 
A

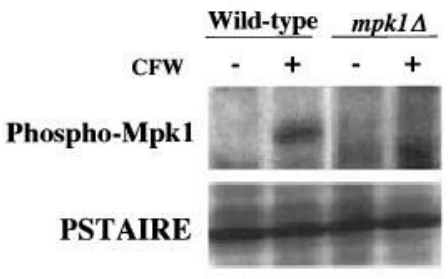

B

Caspofungin Nikkomycin $\mathrm{Z}$

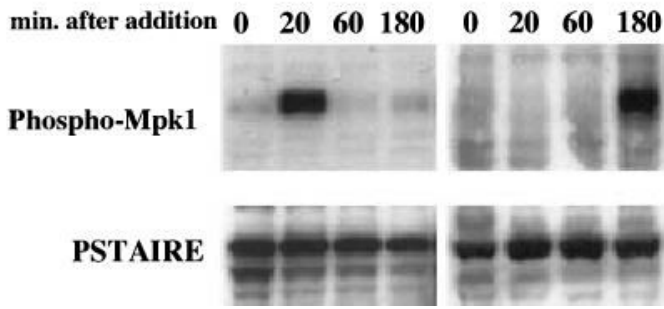

Fig. 3. Perturbation of the cell wall induces Mpk1 phosphorylation

A. C. neoformans Mpk1 is phosphorylated after Calcofluor white treatment. Exponentially growing strains were untreated or treated with $10 \mu \mathrm{g} \mathrm{ml}^{-1}$ Calcofluor white (CFW) for $2 \mathrm{~h}$. Protein was extracted and subjected to immunoblot analysis using antiphospho-p44/p42 antibodies. Anti-PSTAIRE antibodies were used as a loading control. Strains used were wild type (JEC21) and $m p k 1 \Delta$ (PK1).

B. Nikkomycin $\mathrm{Z}$ and caspofungin induce Mpk1 phosphorylation. An exponentially growing wild-type strain was treated with $6 \mu \mathrm{g} \mathrm{ml}^{-1}$ caspofungin or $25 \mu \mathrm{g} \mathrm{ml}^{-1}$ nikkomycin $\mathrm{Z}$, and the phosphorylation state of Mpk1 was determined by immunoblot analysis. 

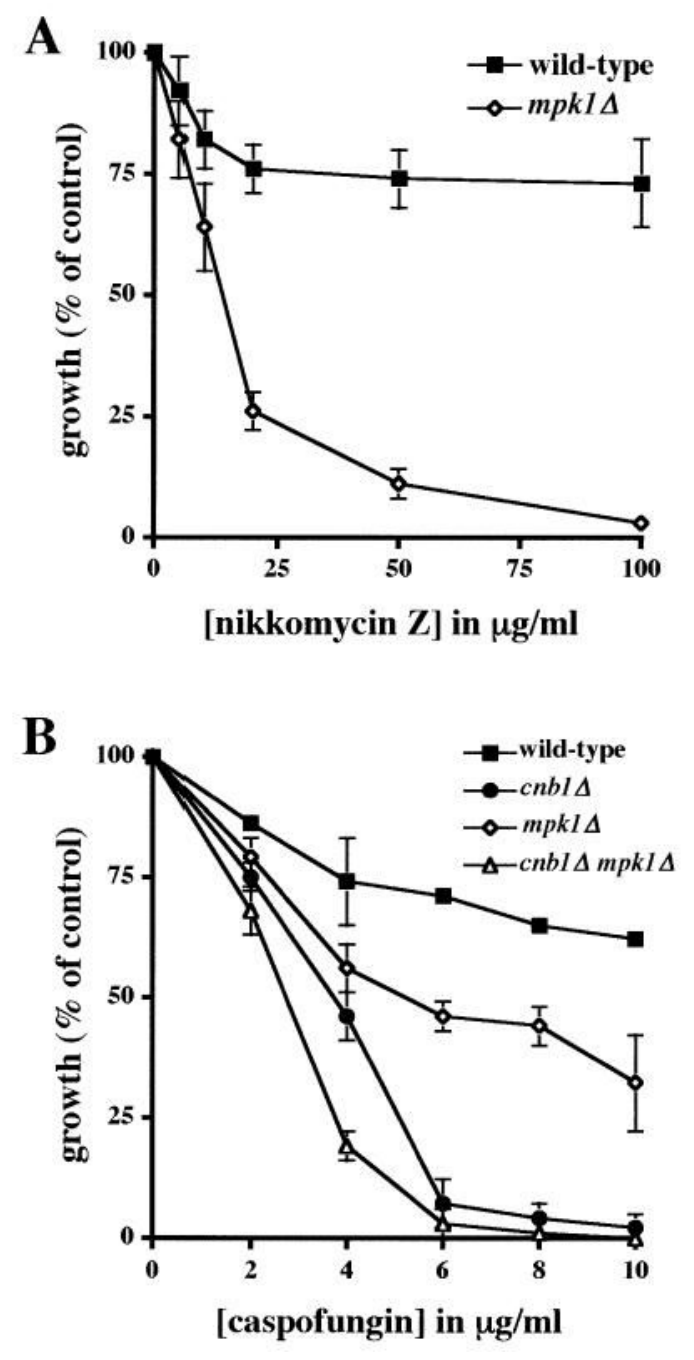

Fig. 4. Enhanced sensitivity of the mpk1 $1 \Delta$ mutant to nikkomycin $\mathrm{Z}$ and caspofungin. Cells were precultured in YPD at $25^{\circ} \mathrm{C}$ for 16-20 $\mathrm{h}$ before dilution to an $\mathrm{OD}_{600}$ of 0.025 . Growth was continued in the presence of nikkomycin $\mathrm{Z}$ or caspofungin in flat-bottomed 96-well microtitre plates at $25^{\circ} \mathrm{C}$ without shaking. Growth was determined after $48 \mathrm{~h}$ as the $\mathrm{OD}_{600}$ of each culture after resuspension. Experiments were repeated four times, and data are represented as the mean and standard error of the mean

A. Strains used were wild type (JEC21) and the mpk1 $1 \Delta$ mutant (PK1).

B. Strains used were wild type (JEC21) and the mpk1 $\Delta$ (PK1), cnb1 $\Delta$ (DSF11) and $c n b 1 \Delta$ mpk1 1 (PK2) mutants. 


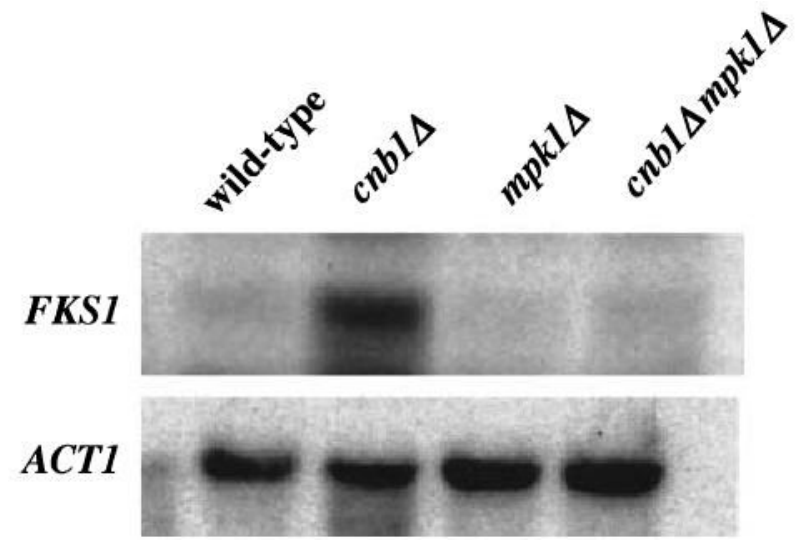

Fig. 5.

Loss of calcineurin function activates FKS1 expression in an Mpk1-dependent manner. Total RNA was extracted from cultures in the logarithmic phase of growth, and the level of FKSI gene expression was analysed by Northern blot using a fragment of the FKS1 gene as a probe. An ACT1 gene fragment was used as a loading control. Strains used were wild type (JEC21)

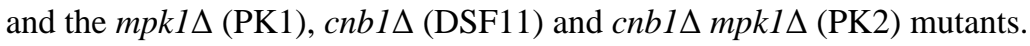




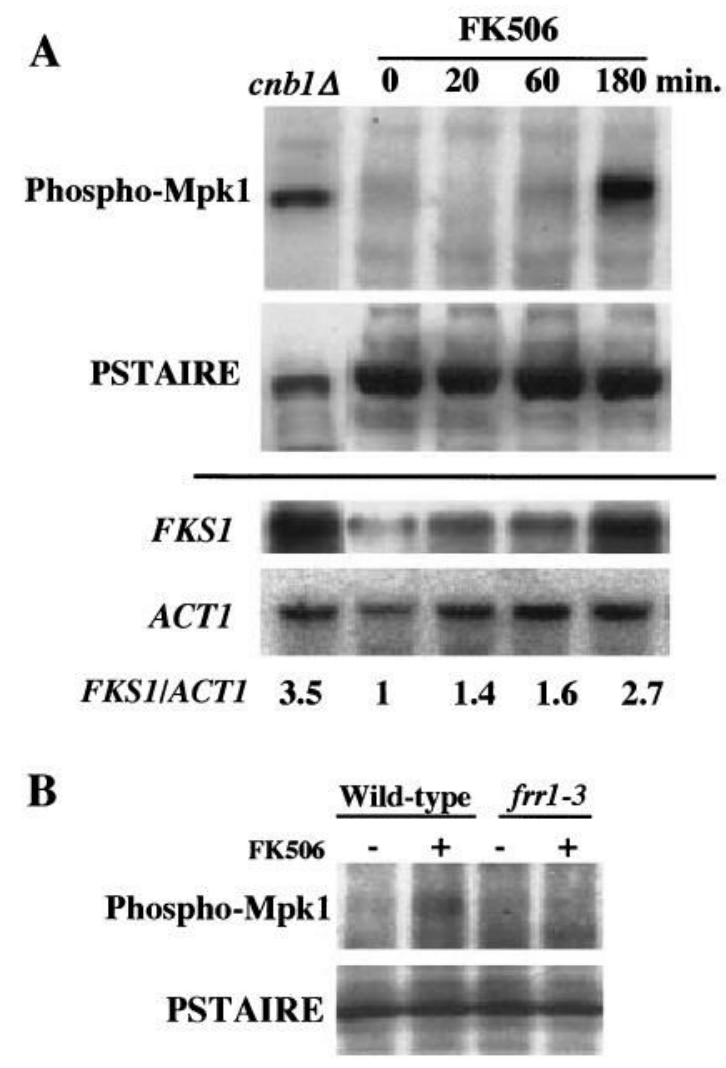

Fig. 6. Inhibition of calcineurin by FK506 causes Mpk1 phosphorylation and FKS1 induction A. Cultures of wild-type strain JEC21 in the logarithmic phase of growth treated with $5 \mu \mathrm{g}$ $\mathrm{ml}^{-1}$ FK506 for 0, 20,60 and $180 \mathrm{~min}$ and an untreated cnbl $\Delta$ mutant strain were assessed for both Mpk1 phosphorylation and FKS1 expression. Proteins were extracted and subjected to immunoblot analysis using antiphospho-p44/p42 antibodies. Anti-PSTAIRE antibodies served as a loading control. FKS1 gene expression was analysed by Northern blot using a fragment of the FKS1 gene as probe and an ACTl gene fragment as the loading control.

B. Cultures of wild-type strain JEC21 and an frrl-3 mutant strain (C21F3) were treated with $5 \mu \mathrm{g} \mathrm{ml}^{-1} \mathrm{FK} 506$ for $180 \mathrm{~min}$, and protein extracts were separated by SDS-PAGE and assessed for Mpk1 phosphorylation as in (A). 


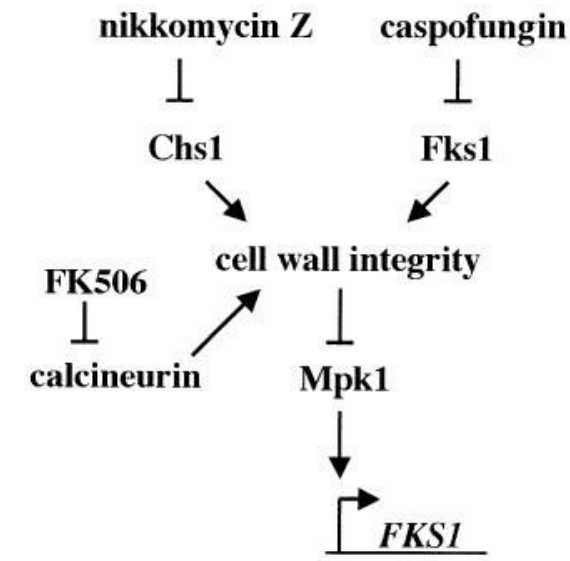

Fig. 7.

Schematic diagram of the $C$. neoformans cell integrity pathway. Chitin synthase (Chs1) and $\beta$-1,3-glucan synthase (Fks1) contribute to the maintenance of normal cell wall integrity, a condition under which the cell integrity MAP kinase pathway is not activated. Nikkomycin $\mathrm{Z}$ and caspofungin inhibit $C$. neoformans chitin synthase and $\beta$-1,3-glucan synthase, respectively, leading to activation of the cell integrity MAP kinase Mpk1. The steps leading to Mpk1 activation may include the activity of cell wall sensors, the $\beta$-1,3-glucan synthase subunit Rho1 and protein kinase $\mathrm{C}$. The Mpk1 pathway is important for survival of $C$. neoformans cells treated with nikkomycin $\mathrm{Z}$ or caspofungin. In the absence of calcineurin, Mpk1 partially protects $C$. neoformans cells from caspofungin treatment. Inhibition of calcineurin by FK506 leads to activation of Mpk1, possibly because of a cell wall defect caused by the lack of calcineurin function. 